\title{
3D models related to the publication: Systematic and locomotor diversification of the Adapis group (Primates, Adapiformes) in the late Eocene of the Quercy (Southwest France), revealed by
} humeral remains.

\author{
Marigó J. ${ }^{1,2 *}$, Verrière N. ${ }^{1}$, Godinot M. ${ }^{1,3}$ \\ ${ }^{1}$ Centre de Recherches sur la Paléobiodiversité et les Paléoenvironnements (CR2P, UMR 7207), Sorbonne Universités (MNHN, CNRS, \\ UMPC-Paris 6), Muséum National d'Histoire Naturelle, Paris, France \\ ${ }^{2}$ Institut Català de Paleontologia Miquel Crusafont, Universitat Autònoma de Barcelona, Cerdanyola del Vallès, Barcelona, Spain \\ ${ }^{3}$ Ecole Pratique des Hautes Etudes, PSL, Paris, France \\ ${ }^{*}$ Corresponding author: judit.marigo@icp.cat
}

\begin{abstract}
The present 3D Dataset contains the 3D models analyzed in the publication "Systematic and locomotor diversification of the Adapis group (Primates, Adapiformes) in the late Eocene of the Quercy (Southwest France), revealed by humeral remains". In this paper, twenty humeral specimens from the old and new Quercy collections attributed to the fossil primates Adapis and Palaeolemur are described and analyzed together. In this dataset only the scans of the fossils belonging to the collections of Université de Montpellier are provided. In our paper (Marigó et al., 2019) we provide a qualitative and quantitative analysis of the different humeri, revealing that high variability is present within the "Adapis group" sample. Six different morphotypes are identified, confirming that what has often been called "Adapis parisiensis" is a mix of different species that present different locomotor adaptations.
\end{abstract}

Keywords: Adapis, humeri, locomotion, Quercy

Submitted:2018-06-19, published online:2018-20-12. https://doi.org/10.18563/journal.m3.75

\section{INTRODUCTION}

The 3D models provided here are the humeral remains attributed to the Adapis group that belong to the collections of the Université de Montpellier (see Fig. 1, Fig. 2, Fig. 3, Fig. 4 and Table 1). The rest of the specimens will be shared through Morphosource once all permissions from different institutions housing the specimens are obtained. The complete sample studied is composed of 20 humeral remains that prove that what is often called "Adapis parisiensis" is a mix of species. We tested variability within the sample though Levene's tests and obtained higher variance than in extant primates of similar size, as well as higher than in primates from the fossil site of Vastan (India), including different genera and different primate groups. Moreover, we demonstrate that the humeral proportions of Adapis overlap with different groups of extant strepsirrhines and platyrrhines depending on the specimen, so the popular view of Adapis as a loris-like slow climbing primate does not apply to the whole sample presented here. Moreover, different humeral features traditionally associated with "Adapis parisiensis" such as the absence of a zona conoidea and a reduced brachioradialis flange are variable depending on the sample studied. In addition, results of our analyses show that adapine and omomyid humeral morphology overlap extensively, leading us to question the accuracy of taxonomic attributions based on morphology of isolated humeri at localities where omomyids and adapines of similar size coexist. Finally, assuming that our different mor- photypes represent different species within two genera, we propose a phylogenetic hypothesis relating these morphotypes, which inhabited a small geographic area.

\section{METHODS}

All specimens were scanned from the original fossil using a Breuckmann 3D surface scanner available at the Plateforme de Morphométrie of the Muséum National d'Histoire Naturelle (UMS 2700, CNRS, MNHN, Paris) with the medium lens. This surface scanner allows the acquisition of the 3D surface of the bone at high resolution using white light fringes (StereoSCAN3D model with a camera resolution of five megapixels).

\section{ACKNOWLEDGEMENTS}

This work has been supported by the CERCA Programme/ Generalitat de Catalunya (research group 2017 SGR 86). Grant sponsor: Fondation Fyssen. Grant number: N/A. Grant sponsor: Ministerio de Economía y Competitividad (MINECO). Grant number: IJCI-2015-26392. Grant sponsor: Ministerio de Economía y Competitividad (MINECO)/FEDER, UE. Grant number: CGL2017-82654-P. We are also really grateful to Raphaël Cornette of the "Plateforme de morphométrie" of the UMS 2700 (CNRS, MNHN, Paris) for access to the surface scanner. We thank Florent Goussard for access to the 

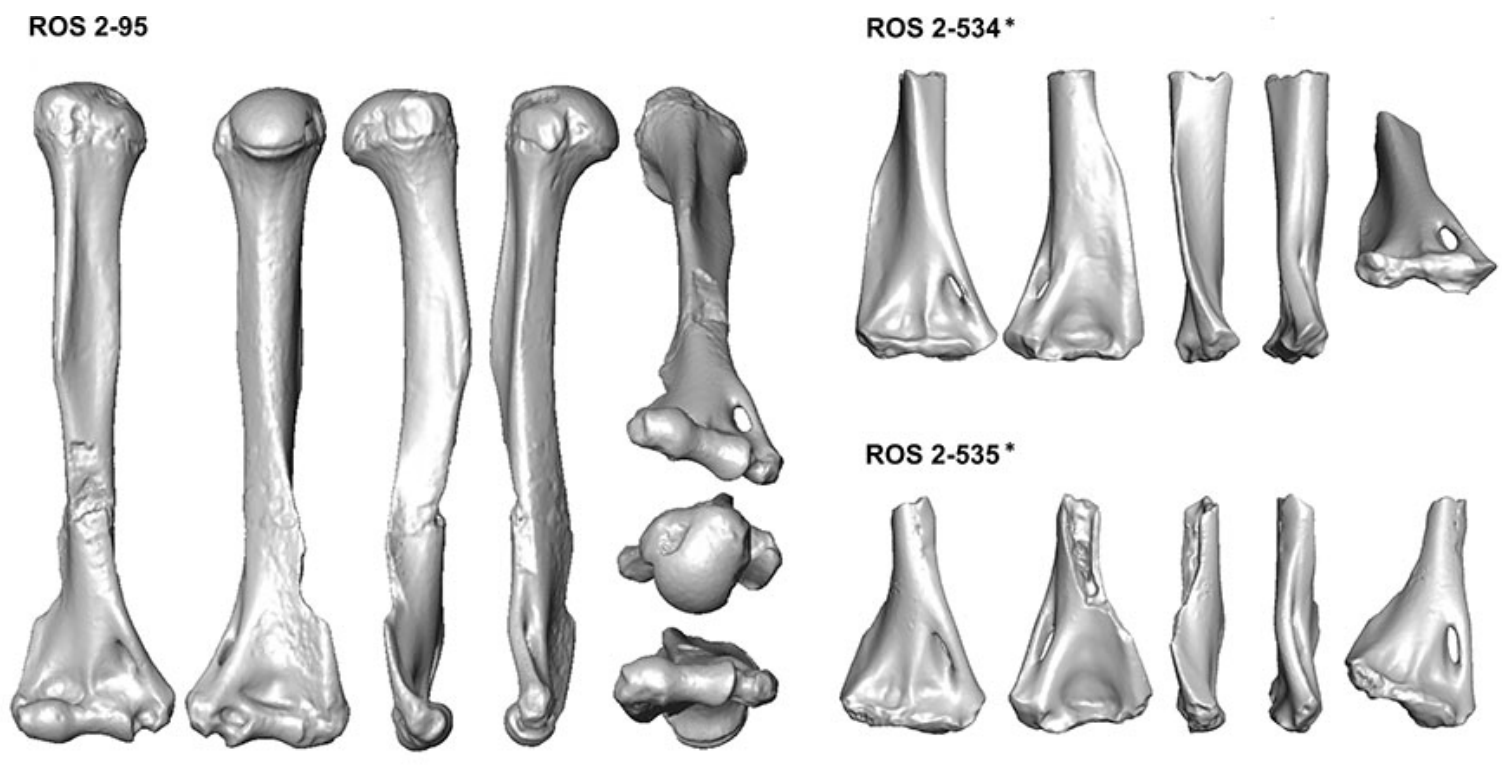

ROS 2-536
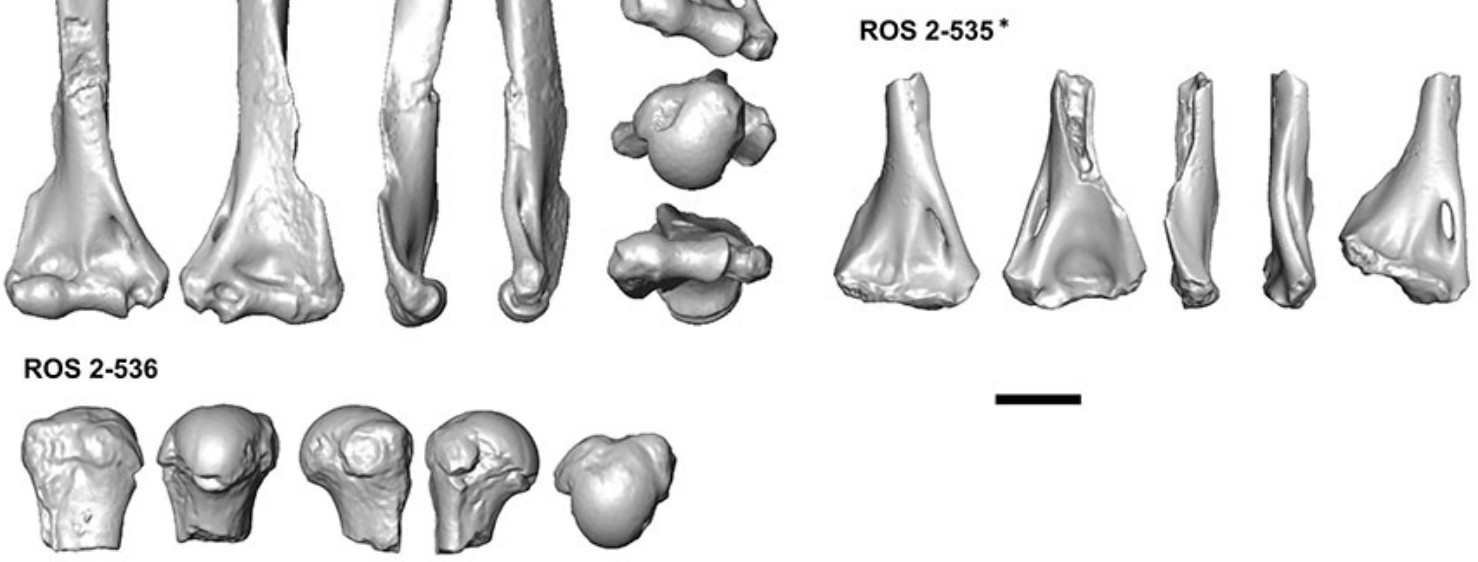

Figure 1. Humeral specimens attributed to the Adapis group assigned to morphotype 1 (M1). UM ROS 2-534 and UM ROS 2-535 are mirrored for comparison purposes. Locality of provenance: Rosières 2 (MP19)

"Salle d'imagerie 3D" of the CR2P (MNHN, Paris) and AnneClaire Fabre for help and advice during surface scanning.

\section{BIBLIOGRAPHY}

Marigó, J., Verrière, N., Godinot, M., 2019. Systematic and locomotor diversification of the Adapis group (Primates, Adapiformes) in the late Eocene of the Quercy (Southwest France), revealed by humeral remains. Journal of Human Evolution. https://doi.org/10.1016/j.jhevol.2018.10.009

\begin{tabular}{|c|c|c|}
\hline Model IDs & Taxon & Description \\
\hline UMROS2-534 & Adapis sp. morphotype 1 & $\begin{array}{l}\text { Distal end } \\
\text { of left } \\
\text { humerus }\end{array}$ \\
\hline UMROS2-536 & Adapis sp. morphotype 1 & $\begin{array}{l}\text { Proximal } \\
\text { end of right } \\
\text { humerus }\end{array}$ \\
\hline UMROS2-95 & Adapis sp. morphotype 1 & $\begin{array}{c}\text { Complete } \\
\text { right } \\
\text { humerus }\end{array}$ \\
\hline UMROS2-535 & Adapis sp. morphotype 1 & $\begin{array}{l}\text { Distal end } \\
\text { of left } \\
\text { humerus }\end{array}$ \\
\hline UMROS2-80 & Adapis sp. morphotype 2 & $\begin{array}{l}\text { Proximal } \\
\text { end of right } \\
\text { humerus }\end{array}$ \\
\hline UMROS2-79 & Adapis sp. morphotype 2 & $\begin{array}{l}\text { Distal end } \\
\text { of the right } \\
\text { humerus }\end{array}$ \\
\hline UMECA1364 & Adapis sp. morphotype 3 & $\begin{array}{l}\text { Distal end } \\
\text { of left } \\
\text { humerus }\end{array}$ \\
\hline UMACQ262 & Adapis sp. morphotype 4 & $\begin{array}{c}\text { Complete } \\
\text { left } \\
\text { humerus }\end{array}$ \\
\hline
\end{tabular}

Table 1. Specimen list 


\section{ROS 2-80}
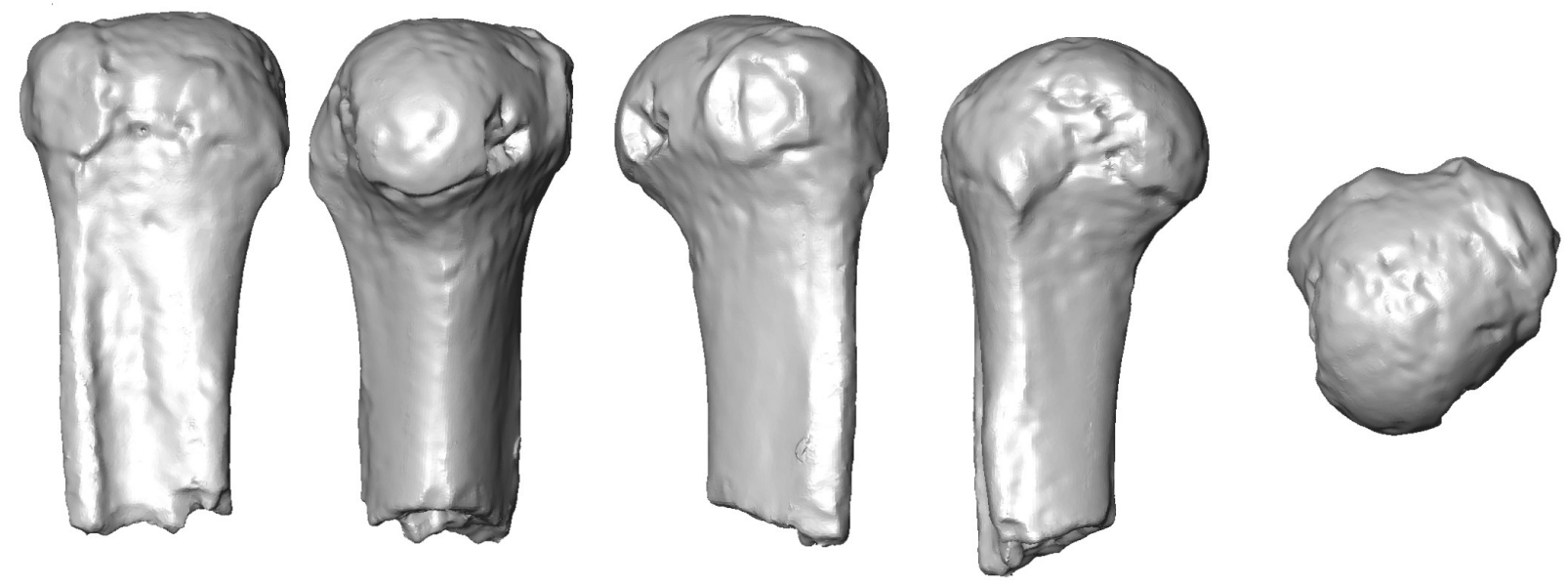

ROS 2-79
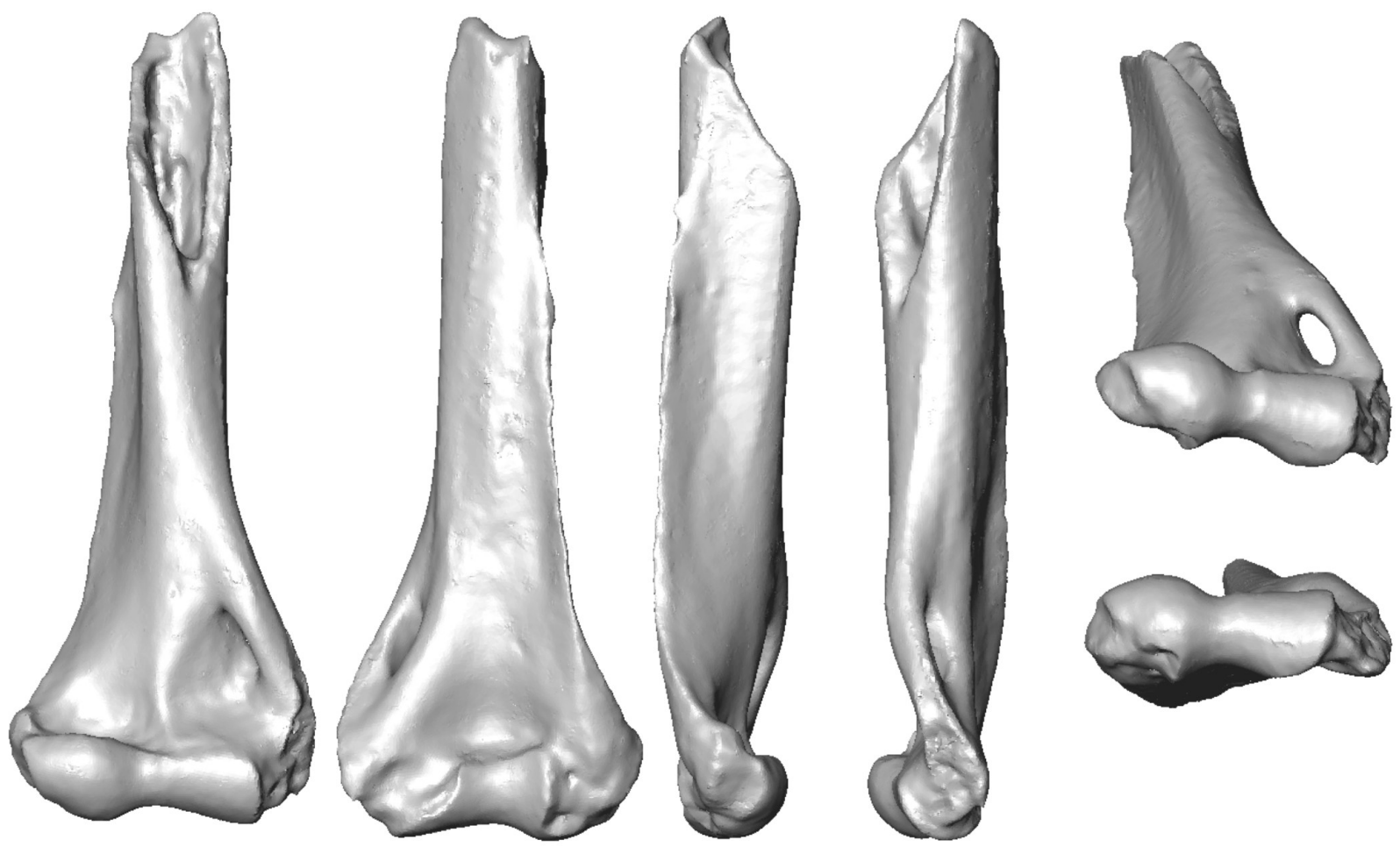

Figure 2. Humeral specimens attributed to the Adapis group, assigned to morphotype 2 (M2). Locality of provenance: Rosières 2 (MP19). 


\section{ECA 1364*}
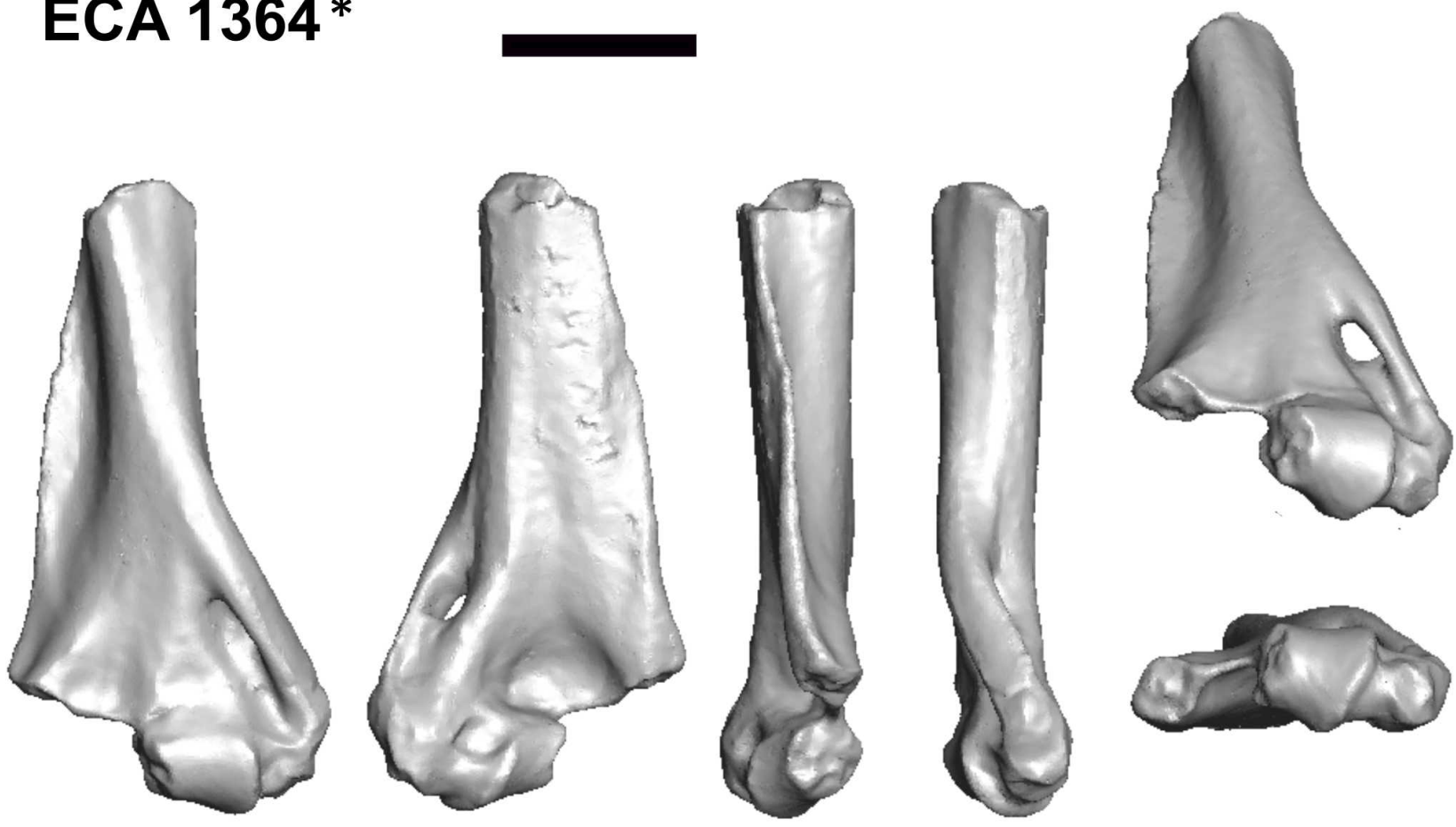

Figure 3. Humeral specimen UM ECA 1364 attributed to the Adapis group assigned to morphotype 3 (M3). This specimen is mirrored for comparison purposes. Locality of provenance: Escamps (MP19). 


\section{ACQ 262*}
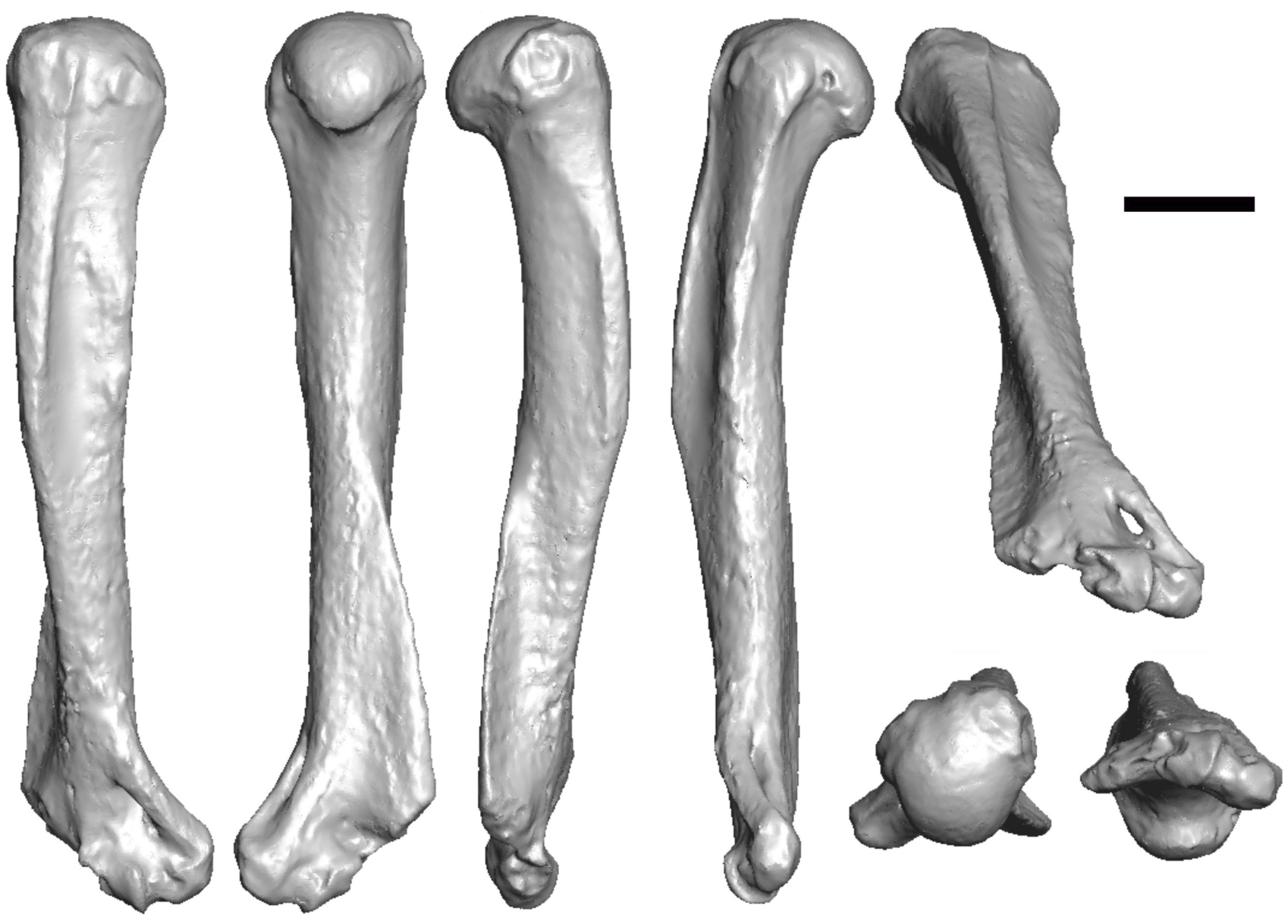

Figure 4. Humeral specimen ACQ 226 attributed to the Adapis group assigned to morphotype (M4). This specimen is mirrored for comparison purposes. Locality of provenance: unknown (old phosphorite collections). 